\title{
The Use of Antibiotics in Hospice and Palliative Care Settings
}

\author{
Aditya C. Shekhar* ${ }^{\dagger}$ \\ ${ }^{*}$ Center for Bioethics, Harvard Medical School, Boston, MA, \\ ${ }^{\dagger}$ The University of Minnesota - Twin Cities, Minneapolis, MN, USA
}

Antibiotics are commonly prescribed medications in the hospice and palliative care setting, as well as in many other healthcare settings. The overuse or negligent use of antibiotics is associated with the harmful consequence of fostering the development of antibioticresistant pathogens. Thus, there is an urgent need to critically examine and audit antibiotic use in all aspects of healthcare. In the status quo, there is a lack of consistent standards and guidelines surrounding the use of antibiotics in hospice and palliative care settings, leading to significant variations in how antibiotics are prescribed and administered in end-oflife care. It is apparent that greater thought needs to go into antibiotic decisions for patients receiving hospice or palliative care, especially considering the harmful consequences of the overprescription of antibiotics. The literature suggests that many clinicians prescribe antibiotics inappropriately for patients who would not benefit from their use or prescribe them without adequate documentation. Clinicians should be deliberate about when they prescribe antibiotics and adhere to the appropriate documentation standards and procedures within their institution or community. Future research should seek to generate generalizable knowledge about which patients will benefit most from antibiotic therapy during end-oflife care.

Key Words: Anti-bacterial agents, Palliative care, Hospice care, Terminal care, Bioethics, Antimicrobial stewardship
Received December 5, 2021
Revised January 27, 2022

Accepted February 9, 2022

\section{Correspondence to}

Aditya C. Shekhar

ORCID:

https://orcid.org/0000-0002-2710-2854

E-mail:shekh046@umn.edu

\section{BACKGROUND}

The discovery and widespread adoption of antibiotic therapies-beginning with Alexander Fleming's discovery of penicillin in 1928-have changed the course of medicine [1,2]. Given their proven effectiveness in treating bacterial infections, antibiotics are widely prescribed. Globally, antibiotics have been estimated to make up roughly $5 \%$ of the world's pharmaceutical market [3]. In hospice and palliative care settings, reports suggest that rates of antibiotic use vary from 4 to $84 \%$ [4].

In addition to being a blessing, the popularity of antibiotics has also been a burden, as pathogens with antibiotic resistance are becoming a growing concern [5,6]. Some have even called antibiotic-resistant bacteria "the greatest risk to human health" [7]. Each year, an estimated 2.8 million individuals are infected with antibiotic-resistant pathogens and 35,000 die from these infections in the United States alone [8]. Reducing the clinical overuse of antibiotics is one method to reduce the burden of antibiotic-resistant pathogens. Given the need to reduce nonessential antibiotic use, there is an urgent need to critically examine and audit antibiotic use in all aspects of healthcare [9]. The status quo is particularly troubling since estimates suggest that a majority of antibiotic use lacks definitive therapeutic 
value $[5,6]$. Currently, there is a lack of consistent standards and guidelines surrounding the use of antibiotics in hospice and palliative care settings [10,11]. This has led to significant variations in how antibiotics are prescribed and administered in end-of-life care [12].

\section{OVERUSE OF ANTIBIOTICS IN HOSPICE AND PALLIATIVE CARE}

There is ample evidence suggesting antibiotics are currently overused in hospice and palliative care settings. One study published in 2013 examined 3,884 patients from the 2007 National Home and Hospice Care Survey and found that approximately $27 \%$ of patients received antibiotic medications, most of whom did not have a documented infection [13]. The finding that antibiotics may be unnecessarily prescribed to recipients of palliative or hospice care has been replicated by other studies. A similar study examined patients discharged from inpatient care to hospice care and found that $21.1 \%$ were prescribed antibiotics and $28.2 \%$ of the patients prescribed with antibiotics lacked a documented infection [14]. A study examining the clinical intentions of antibiotic therapies in $\mathrm{pa}^{-}$ tients discharged to hospice care found that the explicit rationale for antibiotics was documented in just $45.3 \%$ of cases [15]. A recent study of 230 hospice patients treated with antibiotics between April 2019 and September 2020 found that just 42\% of antibiotics were appropriately prescribed; appropriateness was defined as meeting Loeb's Minimum Criteria for Antibiotic Initiation [11]. Even still, among patients appropriately prescribed antibiotics, only $60 \%$ experienced symptom relief [11]. Formal medication reconciliation for end-of-life patients is one way to reduce the unnecessary use of antibiotics in hospice and palliative care settings [16].

\section{GOALS OF ANTIBIOTIC THERAPY AT THE END OF LIFE}

The goals of antibiotic therapy for recipients of hospice and palliative care are different than the goals of antibiotic therapy in a non-hospice patient population. One of the main goals of hospice and palliative care overall is quality of life preservation during patients' final stages of life and letting patients "die with dignity" [17-19]. Because of this, many have argued that the primary goal of antibiotic therapy in hospice and palliative care settings should be symptom relief [20].

Antibiotics are not universally effective at achieving this goal. For instance, many studies have reported variations in symptom relief based on infection type, and there is a consensus in the literature that symptom relief following antibiotic administration is not guaranteed during end-of-life care [4,19,20-22]. For instance, one study examining advanced cancer patients receiving outpatient hospice care found complete or partial symptom relief was achieved in $79 \%$ of patients with urinary tract infections, $46 \%$ of patients with oral cavity infections, $43 \%$ of patients with respiratory tract infections, $41 \%$ of patients with integumentary infections, and $0 \%$ of patients with bacteremia [19]. A systematic review of 11 studies conducted by Rosenberg et al. also showed that patients with urinary tract infections were the most likely to achieve symptom relief [4]. A more recent study from Sweden found the overall rate of symptom relief in end-of-life patients prescribed with antibiotic therapy was around 37\% [22]. When antibiotics were used to prevent or treat sepsis in these patients, however, the rates of symptom relief climbed to 50\% [22]. This could suggest that more severely infected patients benefit the most from antibiotic therapy. It is worth noting that symptom relief is a subjective metric, and some percentage of patients studied by retrospective analyses might have been affected by the placebo effect.

Writing in the journal Bioethics, Ford and colleagues outlined five ethical concerns associated with the use of anti-infective medications during end-of-life care [10]. For instance, do these medications prolong the dying process, are they "incongruent with a short life expectancy and goals of care," do they contribute to resistance among pathogens, and how might their use in hospice and palliative care burden the healthcare system? Ultimately, they concluded that further research is needed.

\section{MOVING TO A CULTURE OF ANTIBIOTIC STEWARDSHIP IN PALLIATIVE CARE}

Antibiotic stewardship is a term used to describe an approach 
focused on optimizing the use of antibiotics in a given clinical setting [23]. Core tenets of antibiotic stewardship include: 1) measuring antibiotic prescribing; 2) improving antibiotic prescribing and use by patients and clinicians with the goal of minimizing inappropriate prescriptions; 3) minimizing incorrect or delayed diagnoses; and 4) ensuring the appropriate antibiotic medication and dose are chosen [24]. Two suggested methods to improve antibiotic accountability in healthcare settings include training for clinicians and strengthening the documentation standards surrounding antibiotic use [24]. Charani et al. [23] advocated making optimum antibiotic use the "path of least resistance" for clinicians. Preliminary evidence suggests this may be an uphill battle [25].

Having said that, conventional antibiotic stewardship can be tricky in the hospice and palliative care setting because the goals of care are different. There are conflicting reports regarding whether antibiotic use directly decreases mortality in end-of-life care [26]. This is likely due to immense betweenpatient variability and differing studies recruiting different numbers of patients who either showed improvement or did not show improvement in response to antibiotic therapy. Moreover, as discussed earlier, symptom relief can also vary immensely. Thus, there will not always be a right or wrong answer when it comes to determining whether antibiotic therapy should be initiated during end-of-life care.

The question of discontinuing antibiotic therapy in end-oflife care is also worth discussing. Stiel et al. [27] examined 88 cases where antibiotic therapy was discontinued. They found that the most common causes of antibiotic withdrawal were patient deterioration (41.4\%), therapeutic insufficiency (25.7\%), and patient wishes (14.3\%). Since frequent evaluation of symptom relief is crucial to ensuring antibiotics are optimally distributed, providers will have to consider withdrawing or discontinuing antibiotic therapy for some patients. These may include patients who are not experiencing sufficient symptom relief to justify antibiotic therapy or patients who are experiencing significant side effects from the antibiotic medication.

\section{AREAS FOR FURTHER RESEARCH}

There are a number of areas where future research could prove beneficial. First, the lack of a documented infection in many antibiotic patients has generally been assumed to be due to providers over-prescribing antibiotics. However, it could also mean there simply is a lack of adequate documentation of infections in recipients of hospice or palliative care, which has been reported before [28,29]. Thus, research examining the motivations and practices of clinicians who prescribe antibiotics would be crucial in precisely understanding how much over-prescribing is actually taking place. Related to this, it would be interesting to understand public perceptions surrounding the use of antibiotics in end-of-life care. One study reported that a significant share of antibiotic end-of-life decisions were based on familial wishes [15]. It is possible that families have incorrect perceptions about antibiotic therapy or that many clinicians do not fully disclose the harms associated with the inappropriate use of antibiotic medications, leading to their overuse.

Given that antibiotics have varying levels of effectiveness in relieving symptoms-based partially on the type of infection -further research aimed at better determining which patients would be good candidates for antibiotic therapy would be invaluable. Ideally, this research would lead to guidelines that take into account a patient's medical history and current situation, as well as the likelihood they would suffer from a given infectious disease during end-of-life care.

Despite having the potential to offer insight, a randomized and blinded clinical trial where patients in one arm are given a placebo or withheld antibiotics may present ethical challenges [30]. However, non-blinded/non-randomized trials or observational studies do present limitations in this particular context. For instance, an observational study comparing patients who choose antibiotic therapy with patients who decline antibiotic therapy would suffer from selection bias. Namely, do patients who decline antibiotic therapy suffer from fewer or less intense symptoms than patients who elect to undergo antibiotic therapy? What other differences might be present between end-of-life patients who accept or decline antibiotic therapy? In any study examining end-of-life care, poignant questions remain as to what inclusion/exclusion criteria and endpoints should be used. 


\section{CONCLUSIONS}

It is apparent that greater thought needs to go into antibiotic decisions for patients receiving hospice or palliative care, especially considering the harmful consequences of the overprescription of antibiotics. The literature suggests that many clinicians prescribe antibiotics inappropriately in patients who would not benefit from their use or prescribe them without adequate documentation. Related to this, there might be a lack of knowledge or concern among patients, their families, and some providers about antibiotic resistance. Providers should be open about effectiveness concerns and antibiotic resistance with patients and families and closely monitor patients for symptom relief. They should be deliberate about when they prescribe antibiotics and adhere to the appropriate documentation standards and procedures within their institution or community. Future research should seek to generate generalizable knowledge about which patients will benefit most from antibiotic therapy during end-of-life care.

\section{CONFLICT OF INTEREST}

No potential conflict of interest relevant to this article was reported.

\section{ORCID}

Aditya C. Shekhar, https://orcid.org/0000-0002-2710-2854

\section{REFERENCES}

1. Dosani S. Penicillin man: Alexander Fleming and the antibiotic revolution. BMJ 2005;330(7481):50.

2. Capote AP, Suarez ALT, Gutierrez MMM, Almarales BRQ. Alexander Fleming and the antibiotic revolution. INMEDSUR 2018;1:72-7.

3. Hamad B. The antibiotics market. Nat Rev Drug Discov 2010;9:675-6.

4. Rosenberg JH, Albrecht JS, Fromme EK, Noble BN, McGregor JC, Comer AC, et al. Antimicrobial use for symptom management in patients receiving hospice and palliative care: a systematic review. J Palliat Med 2013;16:1568-74.

5. Wise R, Hart T, Cars O, Streulens M, Helmuth R, Huovinen P, et al. Antimicrobial resistance. Is a major threat to public health. BMJ 1998;60910.

6. Hulscher ME, Grol RP, Van Der Meer JW. Antibiotic prescribing in hospitals: a social and behavioural scientific approach. Lancet Infect Dis 2010;10:167-75.

7. Spellberg B, Bartlett JG, Gilbert DN. The future of antibiotics and resistance. N Engl J Med 2013;368:299-302.

8. CDC: Antibiotic/Antimicrobial Resistance (AR/AMR) [Internet]. Atlanta, GA: Centers for Disease Control and Prevention; 2020 [cited 2020 Jul 20]. Available from: https://www.cdc.gov/drugresistance.

9. Lee GC, Reveles KR, Attridge RT, Lawson KA, Mansi IA, Lewis JS 2nd, et al. Outpatient antibiotic prescribing in the United States: 2000 to 2010. BMC Med 2014;12:96.

10. Ford PJ, Fraser TG, Davis MP, Kodish E. Anti-infective therapy at the end of life: ethical decision-making in hospice-eligible patients. Bioethics 2005;19:379-92.

11. Clark MD, Halford Z, Herndon C, Middendorf E. Evaluation of antibiotic initiation tools in end-of-life care. Am J Hosp Palliat Care 2022;39:274-81.

12. Oneschuk D, Fainsinger R, Demoissac D. Antibiotic use in the last week of life in three different palliative care settings. J Palliat Care 2002;18:25-8.

13. Albrecht JS, McGregor JC, Fromme EK, Bearden DT, Furuno JP. A nationwide analysis of antibiotic use in hospice care in the final week of life. J Pain Symptom Manage 2013;46:483-90.

14. Furuno JP, Noble BN, Horne KN, McGregor JC, Elman MR, Bearden DT, et al. Frequency of outpatient antibiotic prescription on discharge to hospice care. Antimicrob Agents Chemother 2014;58:5473-7.

15. Servid SA, Noble BN, Fromme EK, Furuno JP. Clinical intentions of antibiotics prescribed upon discharge to hospice care. J Am Geriatr Soc 2018;66:565-9.

16. Fong K, Oravec M, Radwany S. Antibiotic use in hospice patients (S745). J Pain Symptom Manage 2017;53:434-5.

17. Pereira J, Watanabe S, Wolch G. A retrospective review of the frequency of infections and patterns of antibiotic utilization on a palliative care unit. J Pain Symptom Manage 1998;16:374-81.

18. Chochinov HM. Dignity-conserving care-a new model for palliative care: helping the patient feel valued. JAMA 2002;287:2253-60.

19. Reinbolt RE, Shenk AM, White PH, Navari RM. Symptomatic treatment of infections in patients with advanced cancer receiving hospice care. J Pain Symptom Manage 2005;30:175-82. 
20. White PH, Kuhlenschmidt HL, Vancura BG, Navari RM. Antimicrobial use in patients with advanced cancer receiving hospice care. J Pain Symptom Manage 2003;25:438-43.

21. Vitetta L, Kenner D, Sali A. Bacterial infections in terminally ill hospice patients. J Pain Symptom Manage 2000;20:326-34.

22. Helde-Frankling M, Bergqvist J, Bergman P, Björkhem-Bergman L. Antibiotic treatment in end-of-life cancer patients-a retrospective observational study at a palliative care center in Sweden. Cancers (Basel) 2016;8:84.

23. Charani E, Cooke J, Holmes A. Antibiotic stewardship programmes-what's missing? J Antimicrob Chemother 2010;65:2275-7.

24. Sanchez GV, Fleming-Dutra KE, Roberts RM, Hicks LA. Core elements of outpatient antibiotic stewardship. MMWR Recomm Rep 2016:65:112.

25. Mitchell SL, D’Agata EM, Hanson LC, Loizeau AJ, Habtemariam DA, Tsai T, et al. The trial to reduce antimicrobial use in nursing home residents with Alzheimer disease and other dementias (TRAIN-AD): a cluster randomized clinical trial. JAMA Intern Med 2021;181:1174-82.

26. Macedo F, Nunes C, Ladeira K, Pinho F, Saraiva N, Bonito N, et al. Antimicrobial therapy in palliative care: an overview. Support Care Cancer 2018;26:1361-7.

27. Stiel S, Krumm N, Pestinger M, Lindena G, Nauck F, Ostgathe C, et al. Antibiotics in palliative medicine-results from a prospective epidemiological investigation from the HOPE survey. Support Care Cancer 2012;20:325-33.

28. Donald L, Lindsay F. Antibiotic stewardship in palliative care - development of antibiotic prescribing guidelines for a hospice inpatient unit. BMJ Support Palliat Care 2014;4(Suppl 1):A62-3.

29. Matthews A, Kirupanadan A, O'Dea R, Duttagupta T, Ferguson J, Kayani S. Antibiotic stewardship in a hospice environment: an audit of start smart then focus. BMJ Support Palliat Care 2018;8(Suppl 2):A52.

30. Juthani-Mehta M, Malani PN, Mitchell SL. Antimicrobials at the end of life: an opportunity to improve palliative care and infection management. JAMA 2015;314:2017-8. 